\title{
Microcephaly-short stature-intellectual disability-facial dysmorphism syndrome
}

INSERM

\section{Source}

INSERM. (1999). Orphanet: an online rare disease and orphan drug data base. Microcephaly-short stature-intellectual disability-facial dysmorphism syndrome. ORPHA:423306

Microcephaly-short stature-intellectual disability-facial dysmorphism syndrome is a rare genetic malformation syndrome with short stature characterized by postnatal microcephaly, failure to thrive and short stature, global developmental delay and intellectual disability, hypotonia, dysmorphic features (short nose, depressed nasal bridge, low set ears, short neck, clinodactyly and cutaneous syndactyly of T2-3 at birth and broad forehead, midface retrusion, epicanthal folds, laterally sparse eyebrows, short nose, long philtrum, widely spaced teeth, micrognathia and coarsening of facial features later in life). Other associated features include postnatal transient generalized edema, myopia, strabismus, hypothyroidism. 